\title{
A Theory-Based Integrative Model for Learning and Motivation in Higher Education
}

Chantal S. Levesque, G. Roger Sell, James A. Zimmerman Missouri Stale University

The shared mission of higher education institutions is to develop educated persons who are able to make connections and build on knowledge acquired across disciplines and fields and through various life experiences. This chapter offers a theory-based model that can be used by researchers and practitioners to enhance academic learning and motivation. Educators can create learning environments that move students from external regulation to self-determined forms of motivation. This model is used to describe conditions that enhance/restrict learning. It also has the potential to be used to interpret research on teaching and learning in higher education.

\section{Introduction}

The central purpose of colleges and universities is to develop educated persons who experience fulfillment as competent, caring, and free human beings. Toward this end, educators can design and implement engaging environments that move students from states of amotivation (without a desire or purpose) and behaviors dependent on external regulation to more self-determined and intrinsic forms of motivation. Highly engaging environments promote effective learning that satisfies basic psychological needs such as competence, relatedness, and autonomy.

In the field of college teaching and learning, theory tends to be dissociated from practice. In addition, researchers interested in learning principles tend to study the mechanics of how people learn. A crucially important aspect 86 
of learning that is often ignored is why people learn. The reasons behind peoples' learning - the motivation for learning - should receive greater attention by education researchers and practitioners.

Svinicki (2004) summarizes speculation about what motivation does for learning: it directs the learners' attention to the task at hand and makes them less distractible; it changes what learners pay attention to; it helps learners persist when they encounter obstacles; and it serves, in the form of goals, as benchmarks that the learners can use to monitor their own learning. Taking the position that "there is no grand or unifying theory of motivation in the psychological literature," she goes on to offer an amalgamated theory of extant "bits and pieces of a theory accumulated over the years" (p. 142) and suggests strategies for enhancing student motivation.

We agree with Svinicki that education can be improved with "good practice" based on research and theory. We also can endorse strategies that Svinicki recommends for enhancing motivation such as being a good role model of appropriate motivation, basing evaluation on progress or absolute level achieved, and providing learners with choice and/or control over goals or strategies.

However, because any eclectic theory attempts to amalgamate or synthesize disparate "bits and pieces" of extant theories, that themselves may be fragmented and have fundamental incompatibilities with other theories, we have taken a different approach to offer another option. We begin with an intact macro or comprehensive theory of motivation that has been elaborated with more than 25 years of sustained empirical research. Using that theory as a foundation, we have created an integrative model to specify and clarify the connections between learning and motivation and to offer a framework that can be used by researchers and practitioners to enhance academic learning and motivation. We use the term integrative in the title to mean three things: conceptualization of learning and motivation into a holistic perspective; use of a model to examine and synthesize research findings focused on learning and/or motivation; and combining of research and practice, the joining of theory with application.

As a springboard for this work, we draw on self-determination theory (SDT) to help interpret and synthesize research on teaching and learning and to describe conditions that enhance and restrict learning. We also link motivation to other key factors in learning such as students' active engagement, prior knowledge and beliefs, information processing approaches to learning, reflection, and self-regulation for learning. We believe that much of what is presented in this chapter can be useful for education from early childhood through adulthood, but our focus is particularly on formal learning experiences in higher education. 


\section{Learning and Motivation Factors in Higher Education}

In this chapter we argue that educators contribute to, but cannot directly cause, student learning. It is for this explicit reason, also aptly expressed by Knapper (2004), that we chose to situate learning strategies and outcomes at the center of our model (see Figure 7.1). Briefly, and to be discussed more fully, the major influences of the educator on learning are through the design of learning environments (considering social-cultural aspects as well as physical setting) in which students interact with content, the educator, peers, and others, and the implementation of strategies that help guide the student toward realizing the intended learning outcomes. Within this model, learning activities occur in the immediate academic environment of the classroom (including laboratories, studios, etc.) as well as in settings beyond the classroom and campus.

FIGURE 7.1

A Visual Representation of an Integrative Model for Learning and Motivation

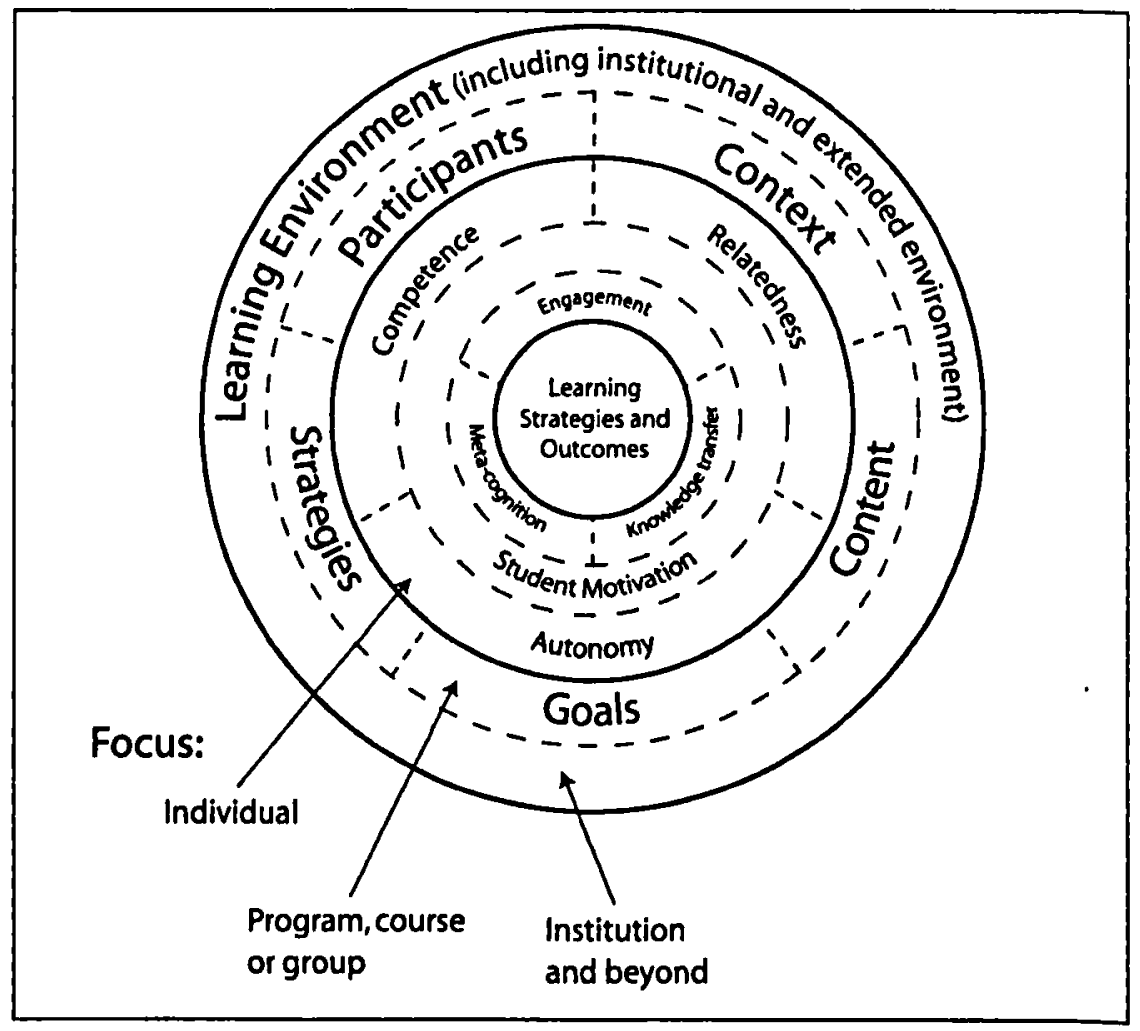


A major premise for our model is that the overarching goals of the educator and the institution should be to create learning environments that enhance students' satisfaction of basic psychological needs and to positively affect student motivation that increases the quality of the students' learning experiences and the outcomes attributed to those experiences.

We contend that effective learning is a self-regulated process. It is internal to the person and thus cannot be caused by an external source. Because learning involves changes that occur within the person, effective learning that is useful and long-lasting engages individuals in a process characterized by selfdetermination (volition) and meaningfulness.

With these premises, definitions, and assumptions, one of the most important questions is: How do we create learning environments that fulfill basic psychological needs and facilitate effective learning?

We propose that effective educators are those able to create learning environments which draw upon and lead to the satisfaction of needs for competence, relatedness, and autonomy. As portrayed in Figure 7.1, educators make decisions and carry out activities that influence five important facets of the learning environment: participants (educators and students), context (immediate setting), content (subject matter), goals (objectives and tasks), and strategies (methods and technologies). Although conceptually distinguishable from one another, these five facets of the learning environment are deeply intertwined, each one affecting and interacting with the others.

\section{-Participants}

Participants are the individuals directly involved in learning activities aimed at explicit goals and objectives. The central participants in the formal learning environment of a college or university are students and educators. At times, and depending on the course or program of study, others within the institution (e.g., staff and administrators) and practitioners beyond the institution (e.g., in community service-learning) also may be included as participants. Critical to the definition of participants are characteristics that affect their abilities and actions in the learning environment. Some key individual characteristics include prior knowledge, beliefs, self-regulatory skills, and emotional states. For example, students' prior knowledge and experiences affect how they perceive, understand, and integrate novel information. Similarly, an educator's epistemological beliefs regarding the nature of knowledge and intelligence subsequently affect his or her teaching approach as well as the extent of the help he or she is willing to provide to students. 


\section{Context}

Within this model, context is defined as the immediate learning milieu both within and outside the classroom in which the participant functions on a day-to-day basis. In contrast to the internal focus in the definition of participant, the definition of context has a decidedly external focus. For example, an individual's emotional state is internal to the person and in the domain of the participant, while the immediate learning environment that affects a participant's current emotional state is external to the person and in the domain of what we define as a participant's context.

\section{Content}

Content refers to the subject matter and topics that are part of the learning environment. Content is the substance or the "what" that educators teach and students learn and, therefore, influences both the objectives and strategies for learning activities. Content includes the declarative, procedural, and conditional knowledge of a discipline or field of study. Learning objectives in our integrative model are addressed within the goals facet of the learning environment.

\section{Goals}

Our definition of goals is not limited to educator-defined course or program goals, but also includes student-defined goals as well as the personal learning aspirations of the educator and students. Goals are the aims or intended outcomes of one or more learning experiences. Educator-defined and studentdefined goals and learning objectives affect the strategies that both the educator and students select and adopt in order to achieve those goals.

\section{Strategies}

Within our model, we define strategies as the ways in which students and educators proceed in order to attain their goals. Strategies include teaching and learning approaches, work habits, time management, and goal-setting, as well as cognitive and metacognitive activities used to direct learning and classroom behavior. The characteristics of participants, context, content, and goals interact with the strategies that students and educators use in their learning and teaching activities.

\section{z Institutional and Extended Environments}

In our integrative model the broader learning environment includes the institution and its culture, as well as the extended external environment (i.e., the 
world outside the institution). In Figure 7.1, the relationship between the larger learning environment and the five facets of the more immediate learning environment is shown as porous and interactive. For example, the larger, more extended learning environment includes features such as the institutional setting and culture, as well as its mission and goals. Because the institutional environment interacts with and influences the more immediate learning environment, the alignment of institutional purpose, mission, and priorities with course offerings, curriculum design, student expectations, and faculty incentives and rewards is crucially important.

\section{Summary}

The five facets of the immediate learning environment are deeply intertwined. Educators both design and implement interconnections among these different facets of the learning environment that influence whether and to what extent the three basic psychological needs of participants are met. Educators act on their perceptions of how, for instance, student personal characteristics, preferences, and beliefs affect the content and learning objectives emphasized in a course. From the student perspective, we can examine how prior knowledge and experiences affect the adoption of learning objectives and strategies to reach those goals and, particularly, different motivational states for learning. A major issue that presents itself for empirical investigation is not which one of the facets of the learning environment is most important but rather how the various facets interact with one another to affect motivation and learning. Another major issue is how the larger institutional and external environment influences the more immediate learning environment. This includes opportunities and constraints educators encounter in attempting to create powerful learning environments that fulfill the three basic psychological needs of participants by drawing upon strategies that integrate the five components of the immediate learning environment proposed in our model.

\section{Self-Determination Theory}

Self-determination theory (Deci \& Ryan, 1985, 2000) is a humanistic, personcentered motivational theory that can help interpret and integrate different research findings and to understand and enhance student learning. As discussed in this chapter, research-based learning principles have been uncovered through empirical methods mostly conducted in disparate studies. Extant studies tend to be informed by mini-theories but without an overarching theoretical framework to help guide research and the application of 
research findings to teaching and learning practices. A theory such as SDT can help specify conditions under which learning will flourish, leading to positive learning outcomes. In short, SDT provides a comprehensive theoretical path from motivational antecedents, to motivational processes for learning, to learning and psychological outcomes.

\section{Overview}

Self-determination theory helps specify and explain ways in which the learning environment can be designed to fulfill fundamental human needs and increase motivation for positive learning outcomes. With reference to Figure 7.1, SDT thus serves to interpret the movement from the outer to the inner circles of our integrative model for learning and motivation in higher education.

SDT postulates three basic psychological needs and proposes that the extent to which these needs are satisfied depends on the degree of self-determination as perceived by the individual. SDT also identifies a continuum of motivational states-from amotivation to extrinsic motivation to intrinsic motivation-and hypothesizes that the degree of self-determination and satisfaction of basic psychological needs varies from low to high across the motivational states.

\section{: Basic Psychological Needs}

Self-determination theory proposes three basic psychological needs that are generalizable across individuals and cultures: autonomy, competence, and relatedness.

Autonomy refers to the volitional endorsement of the reasons behind one's behaviors and actions. Autonomy involves volition (choice) and the desire to organize and behave in a way that is consistent with one's sense of self. Researchers and scholars have often confused the need for autonomy with the concept of independence, which is considered a Western construct. Autonomy signifies choice, and the consequences of choices, not independence. An individual could choose to be interdependent or to do something for someone else, or in contrast could feel pressured to act independently.

Competence refers to the ability to interact effectively with one's environment. Competence is similar to self-efficacy which is the central construct in self-efficacy theory (Bandura, 1997) and Bandura's conceptualization of motivation. It is the belief that one is able to effectively accomplish tasks or perform certain behaviors.

Relatedness refers to connections to and attachments with other people. Relatedness signifies a sense of belonging or affiliation with others. It involves 
secure relationships necessary for autonomy and competence needs to be fully satisfied.

Deci and Ryan $(1985,2000)$ make a clear distinction between needs and motives. Psychological needs are in a way similar to physiological needs insofar as they require satisfaction for individuals to be healthy. Deci and Ryan $(1985,2000)$ argue that, for people to develop, grow, and experience wellbeing, psychological needs are to be satisfied on a daily basis. Within SDT, psychological motives are not considered inherent characteristics of individuals but rather function more as wants than as needs. Motives are certainly powerful in their influence on behavior, but SDT contends they are not essential for psychological well-being when compared to the needs for autonomy, competence, and relatedness.

Deci and Ryan (2000) do not propose that SDT covers all human needs. They acknowledge that physiological needs (e.g., food, shelter, clothing, and sex) and acquired psychological motives (e.g., abasement, achievement, and dominance) are not included in the three innate psychological needs (Deci \& Ryan, 2000).

Although all three basic psychological needs are important for well-being and effective behavior, SDT seems to hold, at least implicitly, that the need for autonomy may be the most central. Research has shown that increased competence in an environment that does not support the need for autonomy will not result in higher levels of self-determination, increased performance, or greater transfer of learning in real-life situations (Deci \& Ryan, 2000; Levesque, Zuehlke, Stanek, \& Ryan, 2004). Positive feedback and increased competence are more likely to result in effective learning and performance when abilities-knowledge, skills, and sensitivities-are developed in an autonomy supportive context. For example, even if an educator is very good at communicating content to students and increasing their subject matter knowledge, the learning may not be translated into improved retention of content or in real-life situations unless the learning occurs in an autonomy supportive educational environment.

\section{: Role of the Environment}

According to self-determination theory, optimal development and well-being will be fostered under environmental conditions that promote competence, relatedness, and autonomy and hindered in environmental contexts that do not satisfy the three basic needs. More than 25 years of research has uncovered key situational factors that either hinder or enhance the satisfaction of these basic psychological needs and self-determination. 
Generally, satisfaction of basic needs will be undermined in situations in which rewards, threats, evaluations, and deadlines are salient (Amabile, DeJong, \& Lepper, 1976; Harackiewicz, Manderlink, \& Sansone, 1984). Those situations are not perceived as autonomy supportive. This is because external incentives, such as rewards, are usually perceived by the target recipient as an attempt to control her or his behavior. Early research examining the use of rewards to coerce performance of an intrinsically motivating activity tended to demonstrate an undermining of intrinsic motivation. Further research showed that this undermining effect is not limited to intrinsic motivation but also extends to self-determined motivation more generally. For example, at the elementary education level, tokens, gold star awards, and standardized tests tend to decrease intrinsic motivation for learning (see Amabile et al., 1976; Deci, Koestner, \& Ryan, 1999, for a review; Deci \& Ryan, 2000; Grolnick \& Ryan, 1987). Similarly, at the college level, frequent evaluations, standardized tests, rewards, threats, and deadlines also tend to undermine intrinsic motivation for learning and self-determination (Deci et al., 1999). External motivators not only can undermine intrinsic motivation but also can stifle creativity, cognitive flexibility, conceptual learning, and complex problem solving (Amabile, 1982; Deci et al., 1999; Grolnick \& Ryan, 1987; McGraw \& McCullers, 1979), characteristics valued in lifelong learners.

Alternatively, contexts in which people are provided with choice and options can lead to enhanced feelings of autonomy and, consequently, higher levels of self-determined motivation and better performance (Black \& Deci, 2000; Deci et al., 1999; Deci \& Ryan, 2000). Even in situations where choice is not possible (e.g., taking the GRE in order to apply to graduate school), providing a rationale for doing what is required and acknowledging the individual's perspective and feelings often lead to a greater satisfaction of basic psychological needs and, consequently, to better learning outcomes.

Practically, what does it mean to create a positive learning environment that will satisfy students' basic psychological needs? When educators do something as simple as take into consideration what students bring to a learning situation-prior abilities, experience, knowledge, beliefs, and information processing approaches to learning - this can demonstrate to students that their perspective has been acknowledged. These kinds of educator behaviors are perceived as autonomy supportive and enhance a student's sense of self in a learning environment. Educators who use strategies that foster students' active engagement through experiential activities such as service-learning, problem-based learning, and collaborative learning also contribute to the enhancement of the learning environment (Baxter Magolda, 2000; Knapper, 2004). They create an autonomy supportive environment 
where competence and skills can be developed. The use of ConcepTests has been shown to substantially enhance the comprehension of introductory physics concepts (Mazur, 1997). Concept testing involves questions that are posed in the classroom setting along with a few possible answers soon after the educator presents a concept for the first time. Students vote on the possible answers individually, and then are given an opportunity to discuss their answers with other students. Students are encouraged to persuade their fellow students that they are correct. After these discussions subside, the students are asked to individually vote again. In terms of SDT, concept testing contributes to increased feelings of competence by allowing students to test their knowledge on a regular basis in a nonthreatening environment (i.e., outside of a formal testing situation). Students are encouraged to reflect on their own learning and the process by which they gain new knowledge and understand new concepts. Similarly, when students are asked to keep a journal or reflect on their performance on a test, they can develop skills that allow them to take ownership and feel autonomous about their own learning.

\section{:Summary}

We have defined learning as both process and outcome. As a process, learning is internal to the individual and thus cannot be forced or caused. As an outcome, learning is a change that happens within the individual. Significant learning that persists and transfers is substantially self-determined.

The motivation to learn is present in every human being at birth. Naturally, toddlers explore their environment out of interest and curiosity. As educators, we are drawn into a profession that is called upon to foster this natural tendency to learn and to grow, to seek fulfillment of basic psychological needs (autonomy, competence, relatedness), and to seek self-actualization.

In its purest form, learning is intrinsically motivated. It is primarily through intrinsic motivation (as well as curiosity and challenge) that individuals reach deeper levels of self-fulfillment (or, in Maslowian terms, higher levels of self-actualization). However, formal education necessarily involves extrinsic motivation that can limit and redirect intrinsic motivation.

That learning is not something done to students is of great importance in the development of our thinking and our integrative model. Because learning as a process happens within (not outside) the student, the student needs to feel a sense of ownership in her or his learning efforts. If students do not feel responsible (and influential) for their own learning and do not see the importance and value of what they are learning, their learning outcomes never will 
be internalized or accessible for transfer to other situations. This is because the "agent" of the learning would lie outside the self as opposed to within.

As we argued previously, the educator's primary responsibility is to create and implement environments that foster student learning. The key message here for educators is that learning needs to be sustained not forced, it needs to be fostered not produced. It is not the educator's role to make students learn. It is the educator's role and responsibility to create environments that will help students learn and with increasing responsibility for shaping their own learning. Because learning is a discovery process, educators are there to create environments for this natural process to take place, not to make the discoveries for the students. The educator's role is to create and implement environments that engage students' natural propensity to develop, grow, and learn-and to model learning processes by making them public and available to students.

\section{States of Motivation and Behavior for Effective Learning Derived From Self-Determination Theory}

Motivation means to move or to bring into action. All intentional human behavior, including learning, involves motivation. The study of motivation addresses issues of what (needs and motives) and how (processes) purposive activities are initiated and sustained over time. The study of motivation also is concerned with why (reasons) individuals are moved to act, the time and effort (resources) invested in a goal-directed activity, the characteristics of environments, contexts, and situations (where) that influence motivation, and the learning, performance, satisfaction, and well-being (outcomes) associated with an intentional activity. Simply stated, within our model we treat motivation similar to the concept of learning, as both process and outcome.

When basic psychological needs are met, individuals' self-regulation of behavior becomes more internalized; individuals identify with the reasons for behaving and endorse the behaviors performed. That is, they begin to develop a sense of ownership in their own learning. Various frameworks and theories try to explain motivation relevant to learning and teaching in higher education (e.g., see Svinicki, 2004). One of the major dichotomies and essential distinctions discussed in the motivational literature is between intrinsic and extrinsic motivation.

\section{. Intrinsic and Extrinsic Motivation}

Intrinsic motivation refers to purposive behavior (including learning) wherein the goal (intention) is the action itself (Deci, 1975). Some examples of intrin- 
sically motivated actions are pursuing curiosity, seeking meaning, developing competence, making choices autonomously, and serving others without the promise of external rewards or the threat of punishment. For intrinsically motivated behaviors, satisfaction is inherent in being fully engaged in the activity; the activity is both the means and end for involvement.

In the academic environment, it is worthwhile to try to foster intrinsic motivation, which has been associated with a host of positive outcomes (see Deci et al., 1999 and Pintrich, 2003, for reviews). However, even when learning activities are intrinsically motivating, other forms of motivation that involve instrumental behaviors are salient in a formal education setting. In this chapter we not only emphasize intrinsic motivation but also the experience of self-determination-doing something out of choice as opposed to coercion or obligation. As described below, some forms of extrinsic motivation also can be self-determined. Although intrinsic motivation is the prototype of self-determined behavior, people can act volitionally in responding to externally initiated requirements, not only the self-initiated activities that are personally interesting and enjoyable.

Extrinsic motivation refers to purposive behavior (including learning) wherein the activity is instrumental for reaching a goal that goes beyond the activity itself. Some examples of extrinsically motivated actions are studying to get a good grade (reward), completing a project in order to get a salary increase, participating on a committee to gain status or recognition, and obtaining an advanced degree to get a better job or earn more money. For extrinsically motivated behavior, satisfaction can result from the instrumental outcomes of an activity but not necessarily from engaging in the activity per se.

It is important to reiterate that an activity can be both intrinsically and extrinsically motivated, but the consequences of negative extrinsic motivators may undermine intrinsic motivation and self-determination. That is, when people feel coerced or obligated to engage in a certain behavior or to do a certain task or activity that they find interesting, a decrease in intrinsic motivation is generally observed. People tend to lose interest in an intrinsically motivated activity when they feel pressured to complete it. Similarly, when people feel coerced or obligated to behave in a certain way, they become less selfdetermined toward the activity.

One important contribution of SDT is the multidimensional conceptualization of extrinsic motivation along a continuum of self-determination. Specifically, SDT proposes and empirically supports four different forms of extrinsic motivation in addition to intrinsic motivation and amotivation. Figure 7.2 presents these six kinds of motivation along a continuum of increasing self-determination. The following discussion elaborates on 
Figure 7.2 and on conditions under which learning is affected by different forms of regulated motivation.

FIGURE 7.2

Types of Motivation Along a Continuum of Self-Determination

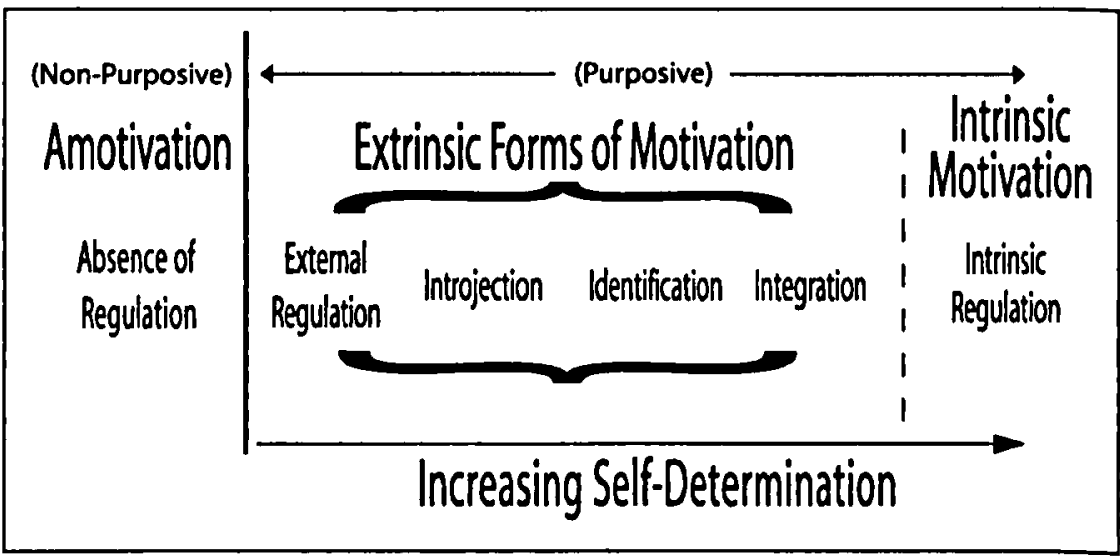

Note. Adapted from Ryan \& Deci, 2000, p. 72.

\section{Amotivation}

For a particular learning situation or course, according to self-determination theory, amotivation is an absence of motivation. This does not mean that the student lacks motivation in general, but rather that the student lacks motivation for a particular learning task. The student could be highly motivated for learning tasks in other courses, for the social life of college, for sports, and so on. This is another way of saying that individuals always have multiple goals, and individuals may have different reasons for pursuing the same goal.

Amotivated students, however, are unable to see the connections between their behaviors and the consequences of those behaviors. This absence of motivation means that engagement in a purposeful activity is not initiated, or that once initiated the activity is disengaged. Amotivated students are not compelled by a reason for their learning or for a particular kind of learning (e.g., they may resist taking a general studies course because they do not perceive the value of taking the course with regard to a job or career).

Externally regulated behaviors are more advanced than amotivated behaviors on the continuum of self-determination. In the context of selfdetermination, it is better to be motivated by rewards and external contingencies than to not be motivated at all. 


\section{1: Extrinsic Motivation and Regulated Behavior}

Many of the behaviors people perform, particularly in an academic setting, are extrinsically motivated. For example, studying for a final examination tends to be extrinsically motivated. However, SDT argues that individuals are naturally motivated to internalize extrinsic motivators when they understand the reasons for their actions. The internalization process also is facilitated by environments that contribute to the satisfaction of the needs for autonomy, competence, and relatedness.

External regulation is the form of motivation commonly understood as extrinsic motivation in the education literature. It is the classic case in which the individual's behavior is controlled by specific external contingencies, such as rewards and punishments. When external regulation is emphasized, individuals do not understand or internalize the values associated with the required behaviors. For example, a student motivated by external regulation would study hard for a major test in order to get an A, or to make sure that his parents keep paying for college, or to impress his educators. External regulation is the least self-determined form of extrinsic motivation.

Introjection is an extrinsic form of motivation in which the external incentives administered by others (i.e., tangible rewards) are partially internalized by the individual. For example, a college student might study hard for an important test to prove to herself that she can do it, or because her sense of self-worth is dependent on the grades she gets, or to avoid feeling guilty or ashamed. This form of extrinsic motivation is interesting because, although it is external to the self, it is partially regulated by the individual himself or herself.

Identification is the process by which individuals begin to internalize the value of their behaviors and to accept them as their own. Identification is more advanced than introjection on the continuum of self-determination because, when behaving out of identification, individuals feel volitional while performing the behaviors. Identification represents an early stage of selfdetermined extrinsic motivation. For example, a student might study hard for a test because she feels it is important to learn the material covered in class, or because she understands that it is important to get a good grade in this class in order to get the job she wants. Inherent in identification is the sense of choice while doing what one is supposed to do. Identification has been consistently associated with positive outcomes such as better conceptual learning and increased creativity.

Integration is the most self-determined form of extrinsic motivation. It not only involves identifying with the behaviors performed and fully endorsing them, but also integrating those behaviors with other aspects of the self. 
For example, a student might choose to study hard on an important test because the act of studying is part of the student's choice to be a responsible student and a lifelong learner.

\section{The Self-Determination Index}

As shown in Figure 7.2, the various forms of motivation can be ordered on a continuum of self-determination. Amotivation is the absence of regulation and self-determination. Considering different forms of extrinsic motivation, external regulation involves the least amount of self-determination and integration the most, with introjection and identification between these two extremes. Intrinsic regulation represents the prototype (or ideal) of self-determination.

Any given activity can be performed for a variety of reasons by a single individual. For example, a student might work hard in a class in order to please the educator (introjection), but also because the student enjoys learning the material (intrinsic motivation) and because this class is covering important information that the student perceives as useful for a future career (identification). To assess the extent to which a student is self-determined toward a particular course or learning experience, we need to pay attention to the student's "relative autonomy" with regard to the type of regulation that occurs with the motivated behavior. For example, a student will experience more positive motivation and learning outcomes for a course if he endorses the self-determined reasons for taking the course to a relatively greater degree than reasons that are not self-determined for taking the course.

Researchers working with SDT have created a Self-Determination Index (SDI) to assess the relative level of autonomy or self-determination for performing any given activity. The SDI is computed by assigning weights to the different forms of motivation as a function of their underlying level of selfdetermination. Since intrinsic motivation, integration, and identification are considered self-determined forms of motivation, they each get a positive weight in the equation. Because amotivation, external regulation, and introjection are considered non-self-determined forms of motivation, they each receive negative weights in the equation. Specifically, the SDI is calculated in the following way:

$$
\begin{aligned}
& \mathrm{SDI}=3^{*}(\text { intrinsic })+2^{*}(\text { integ. })+(\text { iden. })-(\text { intro. })-2^{*}(\text { external } \\
& \text { reg. } \left.)-3^{*} \text { (amotivation }\right)
\end{aligned}
$$

In this calculation, specific weights (from +3 to -3 ) are assigned to the different forms of motivation according to their relative position on the continuum of self-determination. Since intrinsic motivation is the most self- 
determined form of motivation, it receives the highest positive weight. Similarly, since amotivation represents an absence of regulation, it receives the highest negative weight in the equation. The validity and utility of the SDI has been established in studies both within and outside the field of education (see Vallerand, 1997, for a review).

\section{Summary}

The most desirable learning experiences-that is, the ones that fulfill basic psychological needs and have the most positive long-term benefits-involve learning as a discovery process and as a self-determined activity. In the formal context of higher education, not all learning experiences are intrinsically motivated. Learning does not need to be intrinsically motivated to lead to positive outcomes. Environments that help satisfy students' needs for autonomy, competence, and relatedness facilitate the movement of students' motivation from amotivation and externally regulated behaviors toward more selfdetermined forms of extrinsic motivation. By creating learning environments that satisfy students' basic psychological needs, educators can facilitate students' natural propensity to integrate their reasons for behaving and move toward more self-determined forms of motivation. Through this internalization process, externally regulated behaviors become identified and even possibly integrated within the individual, which in turn leads to a host of positive learning outcomes-increased creativity, cognitive flexibility, conceptual learning, and better performance on complex problem solving (Deci \& Ryan, 1991; Deci, Vallerand, Pelletier, \& Ryan, 1991). Therefore, when a behavior is not predominantly intrinsically motivated, which is frequently the case in a formal educational setting, the goal of higher education should be to create environments that facilitate the internalization of extrinsically motivated behaviors instrumental for satisfying the basic psychological needs of autonomy, competence, relatedness. Those positive forms of motivation would in turn foster engagement, knowledge transfer, and the development of metacognition in students, which would then lead to positive learning outcomes.

\section{Concluding Comments}

This chapter discussed essential building blocks of a theory (and philosophy) of learning and motivation in higher education. Our focus has been on formal education and planned learning, which we realize is only part of the larger learning enterprise that can be informal and spontaneous. The work represented in this chapter is a formative attempt to create a conceptual framework 
(model) useful for both research and application that can improve educational systems. Although our focus here has been on students in a formal educational setting, we believe that the principles outlined in this chapter also are applicable to every participant in a learning process (e.g., students, parents, faculty, staff, and administrators). The factors that contribute to the creation of positive learning environments can positively affect individuals at every level of the academic institution.

\section{References}

Amabile, T. M. (1982). Social psychology of creativity: A consensual assessment technique. Journal of Personality and Social Psychology, 43, 997-1013.

Amabile, T. M., DeJong, W., \& Lepper, M. R. (1976). Effects of externally imposed deadlines on subsequent intrinsic motivation. Journal of Personality and Social Psychology, 34, 92-98.

Bandura, A. (1997). Self-efficacy: The exercise of control. New York, NY: W. H. Freeman and Company.

Baxter Magolda, M. B. (2000). Teaching to promote holistic learning and development. In M. B. Baxter Magolda (Ed.), New directions for teaching and learning: No. 82. Teaching to promote intellectual and personal maturity: Incorporating students' worldviews and identities into the learning process (pp. 88-98). San Francisco, CA: Jossey-Bass.

Black, A. E., \& Deci, E. L. (2000). The effects of instructors' autonomy support and students' autonomous motivation on learning organic chemistry: A self-determination theory perspective. Science Education, 84, 740-756.

Deci, E. L. (1975). Intrinsic motivation. New York, NY: Plenum.

Deci, E. L., Koestner, R., \& Ryan, R. M. (1999). A meta-analytic review of experiments examining the effects of extrinsic rewards on intrinsic motivation. Psychological Bulletin, 125(6), 627-668.

Deci, E. L., \& Ryan, R. M. (1985). Intrinsic motivation and self-determination in human behavior. New York, NY: Plenum.

Deci, E. L., \& Ryan, R. M. (1991). A motivational approach to self: Integration in personality. In R. A. Dienstbier (Ed.), Perspectives on motivation (pp. 237-288). Lincoln, NE: University of Nebraska Press.

Deci, E. L., \& Ryan, R. M. (2000). The "what" and "why" of goal pursuits: Human needs and the self-determination of behavior. Psychological Inquiry, 11, 227-268. 
Deci, E. L., Vallerand, R. J., Pelletier, L. G., \& Ryan, R. M. (1991). Motivation and education: The self-determination perspective. Educational Psychologist, 26, 325-346.

Grolnick, W. S., \& Ryan, R. M. (1987). Autonomy in children's learning: An experimental and individual difference investigation. Journal of Personality and Social Psychology, 52, 890-898.

Harackiewicz, J. M., Manderlink, G., \& Sansone, C. (1984). Rewarding pinball wizardry: The effects of evaluation on intrinsic interest. Journal of Personality and Social Psychology, 47, 287-300.

Knapper, C. (2004). Research on college teaching and learning: Applying what we know. Paper prepared for the Teaching Professor Conference, Philadelphia, PA. Retrieved May 17, 2005, from http://teachingprofessor.com/conference/sunday paper.html

Levesque, C., Zuehlke, A. N., Stanek, L. R., \& Ryan, R. M. (2004). Autonomy and competence in German and American university students: A comparative study based on self-determination theory. Journal of Educational Psychology, 96(1), 68-84.

Mazur, E. (1997). Peer instruction: A user's manual. Upper Saddle River, NJ: Prentice Hall.

McGraw, K. O., \& McCullers, J. C. (1979). Evidence of a detrimental effect of extrinsic incentives on breaking a mental set. Journal of Experimental Social Psychology, 15, 285-294.

Pintrich, P. R. (2003). A motivational science perspective on the role of student motivation in learning and teaching contexts. Journal of Educational Psychology, $95,667-686$.

Ryan, R. M., \& Deci, E. L. (2000). Self-determination theory and the facilitation of intrinsic motivation, social development, and well-being. American Psychologist, 55(1), 68-78.

Svinicki, M. D. (2004). Learning and motivation in the postsecondary classroom. Bolton, MA: Anker.

Vallerand, R. J. (1997). Toward a hierarchical model of intrinsic and extrinsic motivation. In M. P. Zanna (Ed.), Advances in experimental social psychology (Vol. 29, pp. 271-360). San Diego, CA: Academic Press. 